\title{
Drug Courts and Community Crime Rates: A Nationwide Analysis of Jurisdiction-Level Outcomes
}

\author{
David R. Lilley \\ University of Michigan-Dearborn, Department of Behavioral Sciences, 4901 Evergreen Road, Dearborn, MI 48128, USA \\ Correspondence should be addressed to David R. Lilley; dlilley@umich.edu
}

Received 29 March 2013; Accepted 31 May 2013

Academic Editor: Todd I. Herrenkohl

Copyright (C) 2013 David R. Lilley. This is an open access article distributed under the Creative Commons Attribution License, which permits unrestricted use, distribution, and reproduction in any medium, provided the original work is properly cited.

\begin{abstract}
Although a substantial number of studies have reported that drug courts reduced the recidivism of graduates (Wilson et al., 2006), a series of recent analyses suggested that drug courts and similar programs were associated with unintended crime outcomes in cities and counties across the nation (Lilley and Boba, 2008; Miethe et al., 2000; Peters et al., 2002; Worrall et al., 2009). Given that over 220,000 offenders participated in this alternative to incarceration and most did not successfully complete the drug court program, jurisdictional crime may have been impacted. A series of panel data analyses were conducted among more than 5,000 jurisdictions nationwide from 1995 to 2002 to assess the impact of drug court implementation grants on UCR Part I felony offenses. Consistent with prior findings, drug court implementation grants were associated with net increases in vehicle theft, burglary, larceny, and some violent offenses. Possible explanations for these unintended outcomes are discussed along with recommendations for adjustments to current drug court programs across the nation.
\end{abstract}

\section{Introduction}

In response to the crack epidemic and soaring crime, congress created the Drug Court Discretionary Grant in 1994 with the goal of expanding this alternative to incarceration to jurisdictions throughout the United States. Within six years, the number of funded adult drug courts grew from 14 to more than 350 and an estimated 220,000 individuals had enrolled in the program $[1,2]$. In recent years, a substantial number of drug court studies have been conducted yielding evidence of recidivism reductions among graduates [3]. However, a series of analyses have also suggested that drug courts and similar programs were associated with unintended crime rate outcomes in cities and counties across the nation [4-7]. Despite these recent findings, at present, it remains unclear which crimes were most affected by drug court grants and to what extent. The primary objective of this study is to take an initial step toward filling these gaps in the research by conducting a series of panel data analyses involving more than 5,000 jurisdictions nationwide from 1995 to 2002 to assess the impact of drug court implementation grants on UCR Part I felony offenses.

\section{Literature Review}

Drug courts were created as an experimental program in Miami, Florida, in 1989 [5]. Objectives of this program were to reduce crime by treating the substance abuse problems of offenders and to provide alternatives to incarceration for individuals who engaged in nonviolent offenses that resulted from drug and alcohol abuse. After preliminary analyses of experimental drug court programs indicated that the backlog of regular criminal trials was reduced and that this program also might also reduce recidivism, Congress allocated funding for drug court grants via the 1994 Crime Act $[8,9]$. These grants (During the initial years of the program, the Byrne discretionary grant program (CFDA 16.580) was used to initiate drug court funding. Additionally, a small number of LLEB grants (CFDA 16.592) were used for drug court implementation. All references to drug court grants in this study include these two additional sources of funding) were used to provide implementation and expansion funds for drug courts in hundreds of jurisdictions throughout the 1990s. As illustrated in Table 1, the first of these implementation grant funds were distributed to city and county jurisdictions in 1995 with annual funds ranging from approximately $\$ 6$ to $\$ 10$ million 
TABLE 1: Drug court implementation grant dollars to local jurisdictions (1995-2001).

\begin{tabular}{lccc}
\hline Year & Sum & Mean & Standard deviation \\
\hline 1995 & 560,750 & 18,667 & 12,220 \\
1996 & 981,868 & 42,351 & 51,940 \\
1997 & $1,577,550$ & 51,272 & 90,421 \\
1998 & $6,560,345$ & 113,345 & 110,056 \\
1999 & $9,780,375$ & 101,255 & 90,590 \\
2000 & $10,899,559$ & 98,300 & 84,037 \\
2001 & $8,971,893$ & 101,030 & 79,452 \\
\hline All & $39,332,340$ & 75,174 & 74,102 \\
\hline
\end{tabular}

$N=1,680$ payments (357 drug court jurisdictions).

Payment observations and funding totals include drug court implementation grants from Byrne, LLEB, and the Drug Court Discretionary grants program.

during peak years, totaling over $\$ 39$ million. During the seven-year period from 1995 to 2001, a total of 1,680 annual drug court implementation grant payments were made to 357 jurisdictions. (The term jurisdiction refers to the primary area of law enforcement coverage by a local (city, county, or township) police agency. Although jurisdictions may have more than one drug court, grant funding was aggregated to the jurisdiction level. Jurisdictions were independent (not nested).) These funds were authorized to support dedicated judges, court personnel, and other expenses related to drug court startup and implementation across the United States.

2.1. Treatment and Program Requirements. The drug court program was designed to last approximately one year and generally consisted of outpatient treatment [10]. During their first decade, the central elements of most drug court programs were attendance at regularly scheduled group counseling sessions and frequent drug testing [11]. Sanctions for noncompliance with drug court rules included verbal warnings from the judge, return to an earlier stage of the program, more frequent drug tests, or incarceration for several days or weeks. However, drug courts were intended to reflect a nonadversarial approach that focused on helping the client $[9,12]$. As a result, participants were typically removed from the program only after multiple and continuous failed drug tests or other noncompliance with rules $[13,14]$. In contrast to punitive programs, under the drug court approach, efforts were made to propel participants toward graduation. Nevertheless, relapses and failed drug tests were expected; thus, program completion frequently required more than twelve months [15].

\subsection{Reasons That Drug Courts May Have Unintentionally} Resulted in Crime Increases. Despite the best efforts of many drug court counselors and officials, several studies have noted that retention of participants has been problematic. A nationwide assessment by the US Government Accountability Office $[11,16]$ found that approximately 60 percent of participants failed to complete the program during the 1998-2002 time period. Authors of another recent study noted that even jurisdictions that threatened noncompliant individuals with incarceration experienced dropout rates as high as 90 percent
[17]. Additionally, several states including, California Florida, and Arizona had laws that forbade incarceration for failing to complete drug treatment [7, 17-19]. Thus, participant addicts who dropped out of these programs often remained unsupervised in the community.

Recent data suggest that more than 40 percent of participants who dropped out of treatment did so within 90 days after entry into the program [20]. Unfortunately, prior research indicates that the recidivism rates of participants who dropped out within 90 days were substantially higher than others [21]. Additionally, there is evidence that probation, rather than incarceration, may have been the norm for noncompliant dropouts in many drug courts [17]. Nevertheless, researchers have reached a consensus that noncompliant dropouts from the drug court program generally have higher recidivism rates than those who graduate from the program [22]. Given that the majority of program participants across the nation did not successfully complete the program, a closer examination of participant drug addiction and criminal involvement is warranted.

\subsection{Participant Drug Addiction and Criminal Involvement.} Numerous studies indicate that drug court dropouts are more likely than graduates to report a serious addiction to hard drugs, such as crack cocaine [15, 23-26]. Unfortunately, criminal justice literature has well-documented the relationship between drug addiction and crime [27-29]. With regard to property offenses, recent data from the National Household Survey on Drug Abuse [30] indicated that drug users were about 16 times more likely than nonusers to report being arrested for larceny and nearly 10 times more likely to have been arrested for vehicle theft within the past year. Additionally, BJS prison survey data indicated that approximately 30 percent of prisoners convicted of burglary and 27 percent of robbery offenders committed these acts to obtain money to purchase drugs [31, 32].

Although the personal and criminal history backgrounds of drug court participants are extremely varied, recent nationwide assessments indicated that the vast majority (nearly 74 percent) of drug court participants had a felony conviction prior to admission $[1,33]$ and that two-thirds of prior convictions were not drug related [11]. Another study that involved random assignment of eligible individuals noted that the average drug court participant had twelve prior arrests [34]. Taken together, these studies suggest that drug court participants were not solely comprised of minor and infrequent offenders, but rather that a substantial portion were involved in serious nondrug-related felonies prior to admission.

Lastly, it is noteworthy that individual drug addiction and related offending can translate into measurable crime rate impacts in communities. In this regard, one recent study found strong evidence of a spatial link between drugs and violent crime at the neighborhood level [35]. Another study found a significant longitudinal connection between minor drug arrests, burglary, and robbery in an analysis of thousands of city and county jurisdictions across the nation [36]. Overall the research linkage between drug use and crime has been strongest for instrumental and property crimes, such as 
vehicle theft and burglary [37, 38]. Consequently, it is hypothesized in the current study that drug court funding will be positively correlated with crime and that associations with property offenses (burglary, larceny, and vehicle theft) will be more consistent and statistically significant than associations with violent offenses in panel data regression models.

\subsection{Prior Drug Court Evaluations. A number of individual} studies and reviews have been conducted to assess recidivism outcomes associated with this program. Systematic reviews and meta-analyses of these studies have noted that most evaluations have been of poor quality, suffer from selection bias, and lack equivalent comparison [11, 39]. For example, many drug court evaluations have compared the outcomes of graduates to those of nongraduates. From a public policy perspective, however, this is an improper metric. Drug court programs must be held accountable for the outcomes of those who drop out of the program as well as those who successfully complete. (The author would like to thank the reviewer for highlighting this important point regarding the inclusion of "intent to treat" outcomes in program evaluation.) Another common problem with prior evaluations involves the "apples to oranges" comparison of participants who remained under drug court supervision with those who were not under any program restriction. One such study utilized the random assignment of treatment and nontreatment groups but then compared the recidivism of individuals who were undergoing routine drug testing, meetings with judges, and other restrictions to those not under treatment, rather than assessing recidivism after program completion [40]. Thus, the potential for equivalent comparison was entirely negated with regard to postprogram recidivism outcomes. Interestingly, this study also found that after 24 months of drug court involvement, only 19 percent of participants had completed the drug court program.

Any rigorous assessment of drug courts should separately assess the postprogram outcomes of both graduates and nongraduates using random assignment or equivalent comparison groups. Moreover, a proper nationwide assessment should include analyses of drug courts in states that have legally restricted the incarceration of noncompliant dropouts, such as California, Arizona, and Florida. More than two decades after implementation, no multijurisdictional evaluation that meets these criteria has yet been conducted.

Although prior evaluations have been incomplete, researchers that evaluated more than 100 individual (mostly program sponsored) studies have reached a general consensus that participants who successfully completed the twelvemonth program recidivated at lower rates after graduation $[21,22,39]$. In this regard, the US Government Accountability Office concluded that drug court graduates in 13 studies were from 4 to 20 percent less likely to be rearrested for any felony or misdemeanor [11]. Additionally, a recent metaanalysis of drug court recidivism studies reported that the overall reduction in rearrests of drug court graduates compared with nongraduates was 26 percent [3]. However, the authors of this meta-analysis also cautioned that only three studies had been conducted using random assignment and noted these studies found a 14 percent recidivism reduction. Another nationwide evaluation of 2,021 drug court graduates reported that only 28 percent were rearrested within two years of completion during the years 1999 and 2000 [22]. In contrast, more than 20 individual evaluations indicated that the recidivism of drug court nongraduate dropouts was substantially higher, ranging from 55 to 86 percent within two years [21].

From a cost-benefit perspective, analysis of net, or total drug court effects, including postprogram recidivism among both graduates and nongraduates, is necessary. In this regard, it is possible that recidivism reductions among graduates in some drug courts may have been substantial enough to offset rearrests by nongraduates. Several individual cost-benefit analyses of varying quality have been conducted that report net benefits during treatment $[3,11,41]$. One such analysis found that the drug court program cost to treat 300 participants was $\$ 1.8$ million compared with $\$ 2.2$ million in the treatment as usual group. Consequently, a saving of nearly $\$ 1,400$ per participant was reported [41]. However, this analysis did not assess postprogram recidivism, victimization costs, or incarceration costs for those removed from the program. Another more comprehensive cost-benefit study was conducted by the Urban Institute utilizing a Bayesian analysis of recidivism and postprogram outcomes [42]. This study found that in-house treatment and incarceration of noncompliant participants led to costs that would exceed the benefits in more than 80 percent of outcome scenarios.

2.5. The Need for This Study. The Office of Management and Budget recently rated the drug court program as "not performing" because it lacked clear outcome measures pertaining to impact on public safety [43]. Although prior studies of recidivism outcomes of drug court graduates have been conducted, no research has yet been published pertaining to net or total drug court impacts on crime rates at the city or county level. Given that drug court programs differ substantially with regard to admission criteria, treatment approach, and incarceration of nongraduates, a nationwide assessment of long-term net crime rate outcomes is needed. Additionally, since most drug court participants had prior nondrugrelated criminal involvement and this program impacted the recidivism of these individuals, declines in UCR Part I offenses may have resulted.

Based on the preponderance of studies of drug court graduates, declines in recidivism among the 220,000 participants could translate into measurable jurisdiction-level crime reductions in locations across the nation that received drug court implementation grants. Thus, one objective of this analysis was to provide a series of tests to determine whether drug court implementation funds were associated with reductions or increases in crime at the jurisdiction level during the 19952002 time period. An additional objective was to increase our understanding of the specific offenses that were most impacted and the extent or relative size of these effects. A final objective was to provide important outcome information to policy makers to aid in the design and implementation of future Department of Justice grants and to provide a starting 
point for criminal justice researchers in their efforts to identify mechanisms of crime reduction that result from federal funding.

\section{Methodology}

3.1. Overview and Assessment of Crime-Related Outcomes. This methodology included a series of panel data regressions to assess changes in annual rates of reported crime as predicted by drug court implementation grant funding during the years 1995-2002. As a result, the impact of annual drug court grant funds on burglary, larceny, auto theft, robbery, aggravated assault, rape, and murder was assessed over time among more than 5,000 jurisdictions. All panel data regressions included fixed effects for both jurisdiction and year to measure changes within each jurisdiction over time [44, 45]. (Jurisdiction fixed effects were generated by time demeaning the variables [46]. This approach facilitates weighted regressions and results in more accurate $R$-square values than the use of dummy variables. Given that neither crime nor grant funding occur in a random fashion and that unmeasured stable jurisdictional characteristics could potentially correlate with the error term, fixed rather than random effects models were more conceptually and empirically appropriate [47].) This methodology has recently been utilized by criminal justice researchers in analyses of the effects of police force size on crime [48] and analyses of the effects of COPS and other grants on crime rates [16, 49-51].

The fixed-effects panel data approach offered a substantial benefit over cross-sectional research in that jurisdictional differences that were stable over time were no longer problematic $[45,52]$. Stated another way, by comparing each jurisdiction with itself at multiple time periods, stable characteristics that were unique to each jurisdiction did not influence the model. Thus, variables such as region, jurisdiction size, and type of government (i.e., municipal or county) were effectively "cancelled out" of the equation because they do not change over time [52].

Similarly, trends that affected all agencies during this era were controlled for by including a numeric year fixed effect or variable in the model [44]. Given the general downward crime trend that occurred nationwide during this era, the inclusion of a yearly trend variable was intended to remove or reduce the influence of this downward pattern from regression results. Consequently, only variables that changed over time and correlated with independent variables in the model were influential and needed to be entered into the analysis with the control variables [45].

In this study, it was anticipated that drug court funding would correlate with funding from a variety of other justice grant programs that were active in each jurisdiction. Therefore, per capita funding amounts from COPS Hiring and MORE, Local Law Enforcement Block Grants (LLEBG), Weed and Seed, and the State Criminal Alien Assistance Program (SCAAP) were also included in the analyses. The resulting panel data models with controls for other federal grants allowed assessment of relationships over time using a methodology that is superior to studies that focus on a single grant program in isolation.

\subsection{Data Sources and Constructed Variables}

3.2.1. Jurisdictional Crime. Annual rates of reported murders, rapes, aggravated assaults, robberies, burglaries, larcenies, and vehicle thefts from each jurisdiction were assessed using Uniform Crime Report (UCR) data that are collected by the Federal Bureau of Investigation [53]. All crime offense data were calculated per 100,000 citizens among jurisdictions that provided full twelve months of data to the UCR program during the years 1995-2002. To facilitate comparison with regard to crime trends, jurisdictions with less than 10,000 residents were removed from analysis. (The removal of these very small jurisdictions did not limit analyses because no jurisdictions of this size received a drug court grant. By 2003, virtually all large- and most medium-sized jurisdictions were covered by a drug court such that meaningful comparison of changes in crime with nondrug court jurisdictions was no longer possible.) The vast majority of these very small jurisdictions did not report much felony crime on an annual basis. The resulting eight-year database represented over 5,000 agencies and nearly 80 percent of officially reported felony offenses in the United States.

State police, campus, airport, and other special police agencies were removed because their jurisdictions overlap with other law enforcement agencies that have primary responsibility for policing these populations. The UCR program refers to state and special police agencies as "zeropopulation agencies" [53,54]. Thus, calculation of crime, arrest, and officer rates per capita are problematic for these agencies.

3.2.2. Grant Funding to Local Jurisdictions. Data pertaining to annual drug court implementation and other grant fundings were obtained directly from the Office of Justice Programs (OJP) comptroller. (The database utilized in this study was developed by a team of criminologists, economists, and data analysts over a two-year period with federal funding. From 2003 to 2006 , federal drug court funding was greatly reduced. However, nearly all courts continued to operate.) More specifically, these data contain annual payment amounts to all recipients of Justice grants from 1990 to 2001. Consequently, these data provided more precise and accurate information pertaining to the distribution of funds than prior studies of justice grants that used award data [16]. Prior studies that used award amounts were forced to estimate the timing of payments from the federal government $[51,55]$. Drug court implementation grants (funded under CFDA 16.585) were available to any jurisdiction that met program design and planning requirements [56]. All grant payment amounts were converted into per capita rates and linked with crime rates and control variables via Federal Information Processing Standard (FIPS) codes that indicate state, county, and jurisdiction location. 
3.2.3. Control Variables. In addition to the grant funding independent variables, demographic and employment variables were included in this analysis to control for contextual changes that occurred annually during the 1990s that may have affected crime rates. Annual county-level employment rates and per capita income were obtained from the Bureau of Economic Analysis. Annual changes in the percentage of population that was aged fifteen to twenty-four (population at risk for offending) and percentage of the population that was nonwhite (a proxy measure for disadvantage) were obtained from the US Census intercensal estimates database and the National Center for Health Statistics [57].

3.3. Panel Data Regression Procedures. There is no single econometric model that can perfectly assess the relationship between drug court implementation funding and crime rates without limitation. Consequently, to ensure that a thorough understanding of these grant impacts was obtained, a variety of alternative models were tested. For example, regressions with and without lagged-dependent variables were tested as well as log transformed and untransformed specifications. Additionally, it was noted that drug court grants were first implemented at a time when crime was trending downward from peak levels in the early 1990s in many jurisdictions. Thus, the years prior to this downward trend (1990-1993) were included in one regression model.

To facilitate comparison of the relative size of grant outcome coefficients while minimizing outlying data, all variables in the primary models were log transformed. The resulting log-log models also allowed interpretation of effects as elasticities-the percent change in the outcome that is expected from a 1 percent in change in grant funding [46]. To affect $\operatorname{logarithmic}$ transformation, the formula $\log (1+x)$ was utilized to address zero values. This approach has become the standard in crime policy studies [46].

Prior analyses of justice grant funding distribution has suggested that a delay in expected outcomes of approximately one year from the time of the initial award is common due to program implementation requirements and federal payment distribution procedures $[16,51]$. Additionally, since funds were received by agencies in various months (often midway) throughout a given year, regression models were conducted using a one-year lag to ensure that outcomes were tested after grant funds were operational. Prior research has suggested that a one-year lag is optimum for the grants included in this study [16]. Moreover, given that the drug court program is designed to require at least twelve months for completion, analyzing only current year grant outcomes would fail to assess postprogram recidivism among graduates.

Given that no single, reliable, and comprehensive list of all drug courts since the beginning of the program currently exists (partial lists of drug courts were obtained from the American University Drug Court Clearinghouse, the National Drug Court Program Office, and the US Government Accountability Office), drug court grants were utilized as a proxy measure for both the timing of drug court startup and relative program size. When compared with available lists of individual drug courts, per capita drug court funding was found to be significantly correlated with counts of total program participants $(r=.631)$ and nearly 99 percent accurate in identifying the year of startup among the 239 courts for which verifiable data were available in existing lists. (Four jurisdictions that operated a drug court were removed from analyses because they either did not receive federal drug court funding or data were missing.)

3.4. Endogeneity and Other Analytic Challenges. There is a possibility that justice grant funding is sometimes influenced by recent changes in local crime rates $[16,48,58]$. For example, increases in crime may lead agencies to seek out additional funding, and falling crime may lead to reductions in grant seeking efforts. To address this problem, four different modeling approaches were utilized. First, it was noted that every jurisdiction that received a drug court grant also received at least one other anticrime-related grant during the 1995-2002 time period. Many of these grants, such as Local Law Enforcement Block Grants (LLEBG) and Weed and Seed grants were specifically distributed to jurisdictions with crime problems. Thus, by including these grants as control variables, correlation with recent changes in crime would be reduced. Second, the effects of more recent or short-term changes in crime were addressed through inclusion of lagged values of the dependent variable as predictors (i.e., from the crime rate in the previous year or two years) in several regression models. This approach has been utilized in a number of recent works $[48,59]$ and offers the added benefit of minimizing autocorrelation [46].

Thirdly, to address longer-term crime trends that may have influenced grant acquisition, data from five years prior to the distribution of drug court implementation grants (1990-1994) were included in some models. Lastly, to address the possibility of "regression to the mean" or a longer-term endogenous relationship, growth quartiles were calculated for all jurisdictions by comparing the change in crime between 1985 and 1992. These years were chosen because they represent the start and end points for the crime increase that occurred in many agencies as indicated by national trends $[60,61]$. Thus, agencies with similar amounts of growth in crime during the late 1980 s and early 1990 s were classified together in four "growth cells" that were interacted with year dummies. Separate growth cells for property and violent crime were included in regressions.

Regression analyses of crime rates frequently include heteroskedastic error. That is, regression estimates are more precise among jurisdictions with larger populations and less precise for smaller jurisdictions. An in-depth analysis of this issue was conducted by Hannon and Knapp [62] who recommended that regressions should be weighted by population and standard errors should be adjusted through the implementation of a heteroskedasticity consistent covariance matrix (HCCM) method. Consequently, most panel data regressions in this study utilized heteroskedasticity robust standard errors and were weighted by population. (Stata software was utilized to generate robust standard errors in all regression models. Other weighting methods were also tested in alternative models.) This weighting method also produces 
TABLE 2: Descriptive statistics for independent and control variables (1995-2002).

\begin{tabular}{lcc}
\hline Variable & Mean & $\begin{array}{c}\text { Standard } \\
\text { deviation }\end{array}$ \\
\hline Independent variables & & \\
$\quad$ Drug court grants (startup, Byrne, LLEB) & 0.02 & 0.24 \\
COPS Hiring grant & 1.61 & 2.86 \\
COPS MORE grant & 0.44 & 1.56 \\
Weed and Seed grant & 0.09 & 0.55 \\
State Criminal Alien Assistance grant & 0.24 & 4.94 \\
Local Law Enforcement Block Grant & 1.14 & 4.05 \\
Control variables & & \\
Pct. nonwhite & 0.19 & 0.14 \\
Pct. age 15-24 & 0.14 & 0.03 \\
Per capita income & 29,312 & 11,777 \\
Employment rate & 0.64 & 0.58 \\
\hline
\end{tabular}

$N=31,041$ annual observations (5,172 agencies).

Independent variables are expressed in dollar amounts per capita.

more accurate nationwide estimates of grant outcomes. Similar methods have been utilized in a variety of recent panel data studies pertaining to crime $[16,51,58]$. Initial tests of logged crime rates were nonstationary. (Initial testing of logged crime rates demonstrated a random walk with a downward trend. The variables used in this study were stationary in first differences) via the augmented Dickey Fuller test. However, consistent with prior findings in criminology $[63,64]$ the variables included in panel data regressions were stationary in first difference form.

3.5. Descriptive Statistics. Tables 2 and 3 list per capita grant amounts and other descriptive statistics pertaining to the predictor and outcome variables in this analysis. The average drug court grant dollar amount was just two cents (\$0.02) per citizen among recipient jurisdictions nationwide. This funding rate was substantially less than other major anticrime programs, such as COPS Hiring (\$1.61), Law Enforcement Block Grants (\$1.14) and Weed and Seed (\$0.09).

With regard to demographic control variables, the average proportion of population that was nonwhite among the 5,172 jurisdictions was 19 percent and the proportion of youth (ages 15-24) was 14 percent from 1995 to 2002. The mean per capita income was slightly over $\$ 29,000$ during the eight-year period, and the average rate of employment for citizens of all ages in reporting jurisdictions was 64 percent.

Table 3 lists the dependent variables and indicates that the greatest portion of crime was comprised of larcenies, which averaged 2,757.4 per 100,000 citizens, followed by burglary (866.4), vehicle theft (502.9), aggravated assault (375.2), and robbery (190.8). The least commonly reported offenses were rape (34.4) and murder (6.9).

\section{Results}

Drug court implementation grant funding to cities and counties nationwide was associated with net increases in vehicle
TABLE 3: Descriptive statistics for dependent variables (1995-2002).

\begin{tabular}{lcc}
\hline Variable & Mean & Standard deviation \\
\hline Dependent variables & & \\
$\quad$ Murder rate & 6.9 & 9.2 \\
Robbery rate & 190.8 & 234.8 \\
Aggravated assault rate & 375.2 & 344.0 \\
Rape rate & 34.4 & 28.1 \\
Burglary rate & 866.4 & 544.3 \\
Larceny rate & 2757.4 & 1695.2 \\
Vehicle theft rate & 502.9 & 485.4 \\
\hline
\end{tabular}

$N=31,041$ annual observations (5,172 agencies).

theft (0.239), larceny (0.051), burglary (0.072), and every other UCR Part I crime category with the exception of murder (Table 4). This relationship persisted when variables pertaining to five other justice grants, economic and demographic changes, and controls for general nationwide trends were included. In this era of generally declining crime, jurisdictions that received greater amounts of per capita drug court funding reported smaller reductions in crime during the years following the grant than jurisdictions that received little or no drug court funding $(P<.05)$. In contrast, none of the five other grant programs were consistently and positively associated with crime.

Demographic and economic control variables in the model yielded, for the most part, expected results. Per capita income was negatively associated with burglary $(-0.882)$, larceny $(-0.571)$, and all other crime types. The percentage of the population that was young (ages 15 to 24 ) was positively associated aggravated assault (4.027), rape (5.152), burglary (4.185), and vehicle theft (9.245). The variables representing percent employed and percent nonwhite yielded mostly mixed and nonsignificant coefficients. Lastly, the control for prior crime growth from 1985 to 1992 indicated that jurisdictions with higher previous crime growth experienced greater crime declines for all offenses except burglary (0.001) and larceny (0.002).

With regard to effect size, the largest and most robust drug court coefficient was found for vehicle theft (0.239). When interpreted as an elasticity, this coefficient indicates that a 1 percent increase in drug court implementation funds was associated with a 0.24 percent increase in vehicle theft. Stated another way, a 10 percent increase in drug court funding was associated with approximately 13 additional vehicle thefts per 100,000 citizens among recipient jurisdictions. (To determine the effect size, a rate of 550 vehicle thefts per 100,000 from the baseline year (1995) was utilized. Using the mean annual amount drug of court funding $(\$ 75,174)$, a 1 percent increase in funding would be approximately $\$ 752$ per year in recipient jurisdictions. The 10 percent increase figure assumes a linear relationship between funding and crime.) Drug court implementation grants were also associated with small increases in rape (0.112), robbery (0.079), and aggravated assault (0.069). It was noted, however, that the association between drug court funding and robbery and aggravated assault was less consistent in the alternative models that are detailed below. 
TABLE 4: The estimated impact of the drug court and other justice grants on individual index crimes (1995-2002).

\begin{tabular}{|c|c|c|c|c|c|c|c|}
\hline Variable & Murder & Robbery & Aggrav. assault & Rape & Burglary & Larceny & Vehicle theft \\
\hline Drug courts & $0.071(1.50)$ & $0.079(2.16)$ & $069(2.07)$ & $0.112(2.66)$ & $\mathbf{0 . 0 7 2}(2.93)$ & $\mathbf{0 . 0 5 1}(2.57)$ & $0.239(6.10)$ \\
\hline COPS Hiring & $-\mathbf{0 . 0 2 1}(3.07)$ & $\mathbf{- 0 . 0 3 7}(4$ & $-0.004(0.59)$ & $0.006(0.069)$ & $-\mathbf{0 . 0 3 0}(4.11)$ & $-0.009(1.68)$ & $-\mathbf{0 . 0 3 3}(3.21)$ \\
\hline COPS MORE & $-\mathbf{0 . 0 7 7}(4.69)$ & $-0.091(6$ & $-\mathbf{0 . 0 2 3}(2.51)$ & $-\mathbf{0 . 0 7 1}(3.57)$ & $-\mathbf{0 . 0 7 7}$ & -0.054 & -0.0 \\
\hline Weed and & $-0.027(1.27)$ & $-0.067(3.96)$ & $-0.062(3.13)$ & $-0.072(3.67)$ & -0.041 & $0.007(1.15)$ & $0.45)$ \\
\hline SCAAP & $-0.052(3.61)$ & $-\mathbf{0 . 0 6 2}(4.37)$ & -0.03 & $-0.025(2.16)$ & -0.04 & -0.032 & .78) \\
\hline Law Enforc. Block Grant & $-\mathbf{0 . 0 8 9}(6.3$ & $-0.111(S$ & $-\mathbf{0 . 0 8 3}(6$ & $-0.053(6$ & $-\mathbf{0 . 0 3 1}(5.81)$ & $-\mathbf{0 . 0 1 0}(2.45)$ & $-\mathbf{0 . 0 5 1}(5.06)$ \\
\hline Per capita income & $-0.674(8.19)$ & $-\mathbf{0 . 5 4 2}(6.59)$ & $-0.462(6.56)$ & $-0.195(2.91)$ & $-0.882(11.7$ & $-0.571(10$ & -0 \\
\hline Age 15-24 & $2.761(3.46)$ & $3.680(4.31)$ & $4.027(6.35)$ & $5.152(5.47)$ & $4.185(6.10)$ & $-0.344(0.87)$ & (9.18) \\
\hline Nonwhite & $2.526(4.31)$ & $-0.197(0.439)$ & $-0.944(1.31)$ & $-2.623(3.16)$ & $-0.834(1.53)$ & $-1.994(5.41)$ & $-0.165(0.39)$ \\
\hline Employment rate & $0.146(0.38)$ & $-0.162(0.41)$ & $0.354(1.33)$ & $0.921(2.67)$ & $0.122(0.61)$ & $0.112(1.55)$ & $0.628(1.49)$ \\
\hline Crime growth cells & $-\mathbf{0 . 0 0 6}(5.15)$ & $-\mathbf{0 . 0 0 8}(6.82)$ & $-\mathbf{0 . 0 1 0}(10.25)$ & $-\mathbf{0 . 0 0 8}(6.06)$ & $\mathbf{0 . 0 0 1}(2.02)$ & $\mathbf{0 . 0 0 2}(4.25)$ & $-0.003(2.16)$ \\
\hline Dependent var. (lagged) & $-\mathbf{0 . 0 7 7}(9.50)$ & $-\mathbf{0 . 0 3 2}(11.30)$ & $-\mathbf{0 . 0 3 3}(9.78)$ & $\mathbf{0 . 1 0 4}(5.71)$ & $-0.001(1.01)$ & $\mathbf{0 . 0 0 3}(5.88)$ & $-\mathbf{0 . 0 0 5}(2.70)$ \\
\hline Constant & $-0.066(1.78)$ & $-0.109(2.90)$ & $-0.084(2.25)$ & $-0.109(2.54)$ & $-0.035(2.11)$ & $0.016(1.37)$ & $-0.062(2.07)$ \\
\hline$R^{2}$ & 0.057 & 0.137 & 0.086 & 0.044 & 0.364 & 0.234 & 0.142 \\
\hline
\end{tabular}

$N=31,041$ annual observations (5,172 agencies).

Coefficients that are significant at the 0.05 level are displayed in bold. Robust $t$ statistics are in parentheses. Jurisdiction and year fixed effects were also included. All variables were log transformed.

TABLE 5: Alternative models of the impact of drug court implementation grants on individual index crimes.

\begin{tabular}{lcccccccc}
\hline Alternate models & Murder & Robbery & Aggrav. assault & Rape & Burglary & Larceny & Vehicle theft & Observations \\
\hline Model 1 & $0.071(1.50)$ & $\mathbf{0 . 0 7 9}(2.16)$ & $\mathbf{0 . 0 6 9}(2.07)$ & $\mathbf{0 . 1 1 2}(2.66)$ & $\mathbf{0 . 0 7 2}(2.93)$ & $\mathbf{0 . 0 5 1}(2.57)$ & $\mathbf{0 . 2 3 9}(6.10)$ & 31,041 \\
Model 2 & $0.025(0.49)$ & $0.031(0.84)$ & $0.042(1.20)$ & $\mathbf{0 . 0 9 2}(2.30)$ & $\mathbf{0 . 0 5 1}(2.11)$ & $\mathbf{0 . 0 4 3}(2.15)$ & $\mathbf{0 . 2 0 2}(5.19)$ & 31,041 \\
Model 3 & $0.070(1.39)$ & $\mathbf{0 . 0 8 2}(2.25)$ & $0.067(1.80)$ & $\mathbf{0 . 1 1 3}(2.77)$ & $\mathbf{0 . 0 7 2}(2.98)$ & $\mathbf{0 . 0 5 4}(2.58)$ & $\mathbf{0 . 2 0 2}(5.12)$ & 31,041 \\
Model 4 & $0.085(1.74)$ & $\mathbf{0 . 0 7 9}(2.22)$ & $\mathbf{0 . 0 6 8}(2.00)$ & $\mathbf{0 . 0 9 8}(2.46)$ & $\mathbf{0 . 0 6 7}(2.83)$ & $\mathbf{0 . 0 6 9}(2.87)$ & $\mathbf{0 . 2 4 6}(6.18)$ & 46,366 \\
Model 5 & $0.096(1.81)$ & $\mathbf{0 . 0 8 5}(2.08)$ & $0.002(0.05)$ & $\mathbf{0 . 1 4 0}(3.13)$ & $\mathbf{0 . 0 8 7}(3.43)$ & $\mathbf{0 . 0 7 4}(3.28)$ & $\mathbf{0 . 1 3 5}(3.23)$ & 1,680 \\
Model 6 & $0.020(0.54)$ & $\mathbf{0 . 0 7 7}(3.47)$ & $\mathbf{0 . 0 8 2}(2.66)$ & $\mathbf{0 . 0 5 3}(2.10)$ & $\mathbf{0 . 0 4 0}(2.10)$ & $-\mathbf{0 . 0 2 3}(1.97)$ & $\mathbf{0 . 1 4 1}(4.43)$ & 6,951 \\
Model 7 & $0.061(1.19)$ & $0.067(1.83)$ & $0.051(1.56)$ & $\mathbf{0 . 1 1 0}(2.73)$ & $\mathbf{0 . 0 6 9}(2.85)$ & $\mathbf{0 . 0 4 7}(2.34)$ & $\mathbf{0 . 2 2 1}(5.68)$ & 31,041 \\
Model 8 & $0.033(0.58)$ & $0.017(0.38)$ & $0.046(1.44)$ & $0.090(1.75)$ & $\mathbf{0 . 0 4 7}(2.20)$ & $\mathbf{0 . 0 4 4}(2.29)$ & $\mathbf{0 . 1 4 9}(4.57)$ & 31,041 \\
\hline
\end{tabular}

Coefficients that are significant at the 0.05 level are displayed in bold. Robust $t$ statistics are in parentheses.

Jurisdiction and year fixed effects were included along with control variables from Table 4. Variables were log transformed in all regressions except for Model 6.

4.1. Alternative Models of the Impact of Drug Court Implementation Grants. Models 1-8 are alternative specifications of the model associated with Table 4:

Model 1: primary model (same as shown in Table 4, 1995-2002),

Model 2: includes drug court funds with no other grants as control variables (1995-2002),

Model 3: no lagged dependent variables included as predictors (1995-2002),

Model 4: same as primary model but includes 13 years of data without prior crime growth cells (1990-2002),

Model 5: includes only drug court jurisdictions (1990-2002),

Model 6: annual drug court grant modeled as binary (received grant $=1$ ) among jurisdictions over 50,000 population (1995-2002),

Model 7: annual drug court grant models weighted by square root of population (1995-2002),
Model 8: includes two lags of the dependent variable, weighted by square root of population (1995-2002).

During the analysis, seven alternative models were tested to ensure that findings were not solely due to one specific methodology (Table 5). Each of these models was included to test a specific attribute of the correlation between drug court funding and crime. Model 2 served as a baseline to identify drug court coefficients when no other grant variables were included in the regression as control variables. This model indicates that the positive association between drug court implementation and crime was not due to an interaction with another major grant program. Model 3 regressions did not include lagged dependent variables. Model 4 included the years prior to the implementation of drug court grants (1990-1994) to demonstrate that the relationship was robust to longer periods of time. Perhaps most importantly, Model 5 was included to rule out the possibility that drug court jurisdictions were simply different in some fundamental way from cities and counties that did not operate a drug court. 
This model included only jurisdictions that received drug court funding. Even among these regressions that solely included cities and counties with drug court programs, jurisdictions that received more per capita funding experienced higher crime relative to the trend for this drug court subgroup. Because per capita drug court funding was correlated with program size, results from Model 5 may indicate that programs with larger numbers of participants (and dropouts) experienced greater net increases in crime.

Models 6-8 were conducted on a post hoc basis to provide additional tests of sensitivity and robustness to modeling changes. To determine whether the initial results could be artifacts of per capita grant dollars or large sample size, drug court grant dollars were recoded as a binary variable such that recipients of annual drug court funds in a given year were coded as "1" (see Table 5, Model 6). In this model that included only larger jurisdictions with over 50,000 residents (resulting in a much smaller $N$ ), the positive relationship between drug court grants and crime persisted for every offense category except murder. Model 7 was conducted with a different weighting, based on the square root of jurisdiction population size. Lastly, Model 8 included two lags of each dependent variable as predictors to minimize the chances of endogeneity due to changes in crime that occurred during the two previous years.

When all models were analyzed together, a positive relationship between drug court implementation grants and crime was found in all models of funding dollars and crime for burglary, larceny, and vehicle theft. Additionally, robbery, aggravated assault, and rape showed positive coefficients that occasionally reached statistical significance. These findings were robust to changes in the years included in analyses, altering or removing different variables, and regressions of drug court jurisdictions separately. Overall, these regressions suggest that the positive relationship between property offenses and drug court implementation was more consistent than that pertaining to violent offenses. Thus, with the exception of rape, the main hypothesis in this study is confirmed. The relationship between drug use and property crime has been well documented in criminal justice literature. Nevertheless, the positive correlation with rape is less well understood but may indicate that drug court participants or dropouts were being victimized while using or seeking illegal drugs. Further analysis of these issues may be found in the Discussion section that follows.

The drug court implementation grant program was the only major anticrime initiative that was consistently associated with crime increases at the jurisdiction level. This is particularly noteworthy given that other initiatives (such as LLEBG, Weed and Seed, and COPS MORE) that were implemented at the same time (and largely among the same jurisdictions) were associated with reductions in crime. Nevertheless, the effect sizes of regression coefficients in this study indicate that the amount of jurisdictional crime increases associated with drug court implementation grants was small to moderate due to the low level of funding (average annual grant payment $\$ 75,174)$, which likely limited program size.

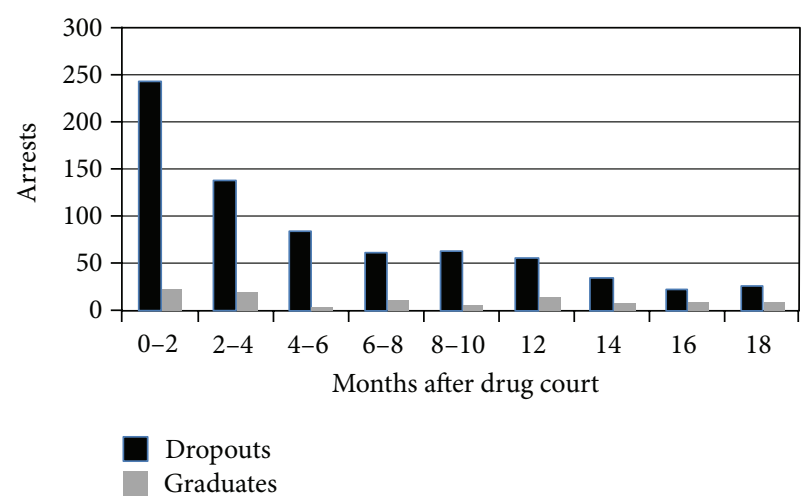

FIGURE 1: Number of arrests per month after drug court (graduates versus dropouts). $N=837$ postdrug court arrests in Southeast County 2002-2004.

\subsection{Post Hoc Analyses and Limitations}

4.2.1. Is There Direct Evidence of Crime by Drug Court Dropouts after Removal? Were noncompliant drug court dropouts efficiently and immediately incarcerated after removal from the program and is there evidence that they actually committed crimes in substantial numbers after removal from the program? To help answer these questions, data from a twoyear follow-up study of discharged participants in Southeast County drug court from 2002 to 2004 were analyzed. (This previous study compared recidivism among graduates and nongraduates within the home county only and thus, reflects an undercount of total recidivism. The two year study took place in a large, well-established drug court in a Southeastern State and was supervised by the first author as part of a separate project.) Of the 1,118 participants, 60 percent (677) did not successfully graduate. A substantial majority of these noncompliant dropouts (408) generated new arrest charges within the county jurisdiction after removal from the program. Additionally, 63 percent of the 1,841 new arrest charges were not drug or alcohol related and nearly one-half of these new charges were felonies. Most importantly, 52 percent of subsequent arrests (380 total) among drug court dropouts occurred within the first four months of removal from the program. The timing of all 837 postdrug court arrests among graduates and nongraduates is illustrated in Figure 1. These arrest patterns clearly indicate that most drug court dropouts in this large, well-established program were not immediately incarcerated after removal for noncompliance.

\subsubsection{Were Preexisting Drug Court Jurisdictional Crime} Trends Simply Different? To rule out the possibility that drug court jurisdictions experienced different preexisting crime trends, Figure 2 was analyzed. This figure clearly indicates that, although crime patterns among drug court jurisdictions were similar to others, declines among grant recipients were actually greater on average. This finding was not unexpected since drug court jurisdictions tended to be located in more urban, high crime areas. It is widely known that areas with high crime experienced the greatest overall declines in crime 


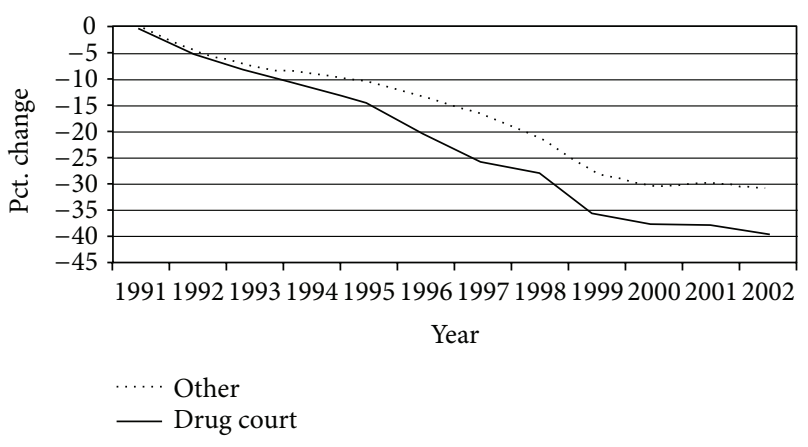

FIGURE 2: Index crime trends among drug court and other jurisdictions (1990-2002).

during the 1990s. However, given that drug court funding increased toward the end of the decade while crime trended downward, these conditions would bias results toward an inverse or negative relationship. As a result, it is apparent that the positive relationship between drug court funding and crime did not merely result from endogeneity or coincidental differences in long-term crime trends. Moreover, the use of a fixed-effect panel data approach allowed analyses of longitudinal changes within each individual jurisdiction (i.e., each jurisdiction at time- 1 compared with itself at time-2, time-3, etc.). Thus, stable cross-sectional differences between jurisdictions could not be the driving factor behind these findings. In this regard, recall that even when drug court jurisdictions were analyzed separately as a subgroup in Model 5, the positive relationship persisted.

4.2.3. Limitations. Given that funds for COPS grants, Weed and Seed, and other anticrime programs were not assigned using experimental design, it is not possible to definitively differentiate causation from correlation. Similarly, the extent to which drug court implementation grants may have acted as a sole cause of crime increases is not entirely clear in this initial assessment. Nevertheless, the key finding in this study is that drug court grants were the only major Justice program associated with net increases in crime remains. Additionally, since other grant funds received by drug court jurisdictions during the same time period resulted in negative coefficients, further examination of drug court community level crime outcomes is needed.

\section{Discussion}

Drug court grants were developed to aid the expansion of alternatives to incarceration for individuals with drug or alcohol addictions that were charged with nonviolent felonies or misdemeanors. Given the general consensus among researchers that drug courts reduced recidivism among many of the 220,000 nationwide participants [3,11], these new drug court implementation grants could have resulted in crime reductions among recipient jurisdictions. Despite this, recent research has indicated that unintended consequences with regard to jurisdiction level crime rates may have resulted [47]. Consistent with recent findings, results of this analysis indicated that drug court grants were associated with net increases in vehicle theft, burglary, larceny, and other offenses. When analyzed together with five other anticrime initiatives, drug court grants were the only program that consistently exhibited this positive correlation with crime.

\subsection{Possible Explanations for the Drug Court Community} Crime Increases. There are a number of potential explanations for the finding that drug court grants were associated with jurisdictional crime increases. Chief among them is that a substantial majority of individuals who entered the drug court system during the 1995-2002 time period did not successfully complete the program [17]. Interestingly, most of these noncompliant individuals were not immediately incarcerated when they failed drug testing or did not attend treatment $[9,33]$. (It is also important to note that many drug court enrollees withdraw participation and thus, are not physically present when sentenced or ruled to be in violation by a drug court judge [9]. Typically, after violations occur, a notice is mailed, followed by a process of seeking an arrest warrant. Issuance of an arrest warrant does not necessarily lead to immediate incarceration.) A key drug court goal is to retain and successfully treat as many offenders as possible. To achieve this objective, drug court systems were put into place that dismissed or removed participants only after multiple, repeated, and continuous failures $[13,14]$. Moreover, as many as 80 percent of drug courts operated in environments where incarceration was not automatic for all participants who were removed for noncompliance $[3,65]$. These factors may have resulted in unintended consequences for the broader community.

Several studies have found that individuals who failed to complete drug court programs were more likely to have extensive criminal histories [15, 66, 67]. These drug court dropouts were also more likely to report serious addiction to hard drugs, such as crack cocaine [15, 23-26]. In this regard, the ramifications of leaving seriously addicted offenders unsupervised in the community for even a few months are difficult to overstate. The extant literature has consistently found that drug court dropouts have higher rates of recidivism than those who complete the program. Indeed, several studies have suggested that dropouts were rearrested at rates from 4 to 9 times greater than graduates [21]. Additionally, post hoc analyses of data from a two-year followup of 1,118 drug court participants provided clear evidence that many noncompliant dropouts were left unattended in the months following removal from the drug court program and generated new offenses (see Figure 1).

The possibility that active drug court participants may have continued to commit offenses during treatment must also be considered. In this regard, for example, one prior investigation found that drug court-approved halfway houses were being used for narcotics trafficking and prostitution [13]. Although this may well have been an aberrant phenomenon, one drug court judge noted that approximately 75 percent of drug court clients failed to meet program requirements during the first two months [68]. Further, as a matter of policy in some drug court programs, individuals were only required 
to be drug free for one-half of the first 180 days of participation to advance into the final phases of the drug court program [13]. If a portion of these individuals continued offending to fund their addictions while active clients of the drug court system, jurisdictional crime may have been affected.

Most drug courts were originally conducted as pretrial diversionary programs. Thus, although participants had been arrested and charged with offenses such as larceny, burglary, and auto theft, they often had not been convicted of these new charges when they entered the drug court system. As a result, the legal basis for immediate incarceration of noncompliant drug court participants was unclear and subsequently challenged in court [18]. In Florida, for example, this legal loophole existed from 1989 to 2006, when the legislature officially gave drug court judges the authority to incarcerate offenders for noncompliance [19].

5.2. Types of Crime Most Consistently Associated with Drug Court Grants. In the current study, property offense increases such as vehicle theft, larceny, and burglary were most strongly associated with drug court implementation grants. This finding is consistent with prior research indicating that illegal drug use increases the instrumental needs of addicts, in part, because intoxication may lower their ability to perform at work or school $[27,28]$. However, there are a number of indirect paths by which drug addiction among noncompliant drug court participants may have been associated with violence as well. In this regard, researchers have noted that drug use may result in reduced self-control and that addicts sometimes take drugs to help them feel more capable of committing crimes [28].

Drug users are also at increased risk of victimization due to vulnerabilities that result from the process of obtaining, ingesting, and coping with pharmacological effects. One study, for example, indicated that 11 percent of regular drug users were victims of forcible sex crimes [29]. Additionally, contact with other drug users increases risk according to nationwide reports from sexual assault victims who often noted that assailants appeared to be under the influence of illegal drugs during the commission of these offenses [31, 32]. Results from these prior studies are consistent with the current analysis, which found a positive correlation between drug court grants and the prevalence of rape. Given recent evidence of a spatial link between drugs and violent crime at the neighborhood level [35], it is possible that addicts who were noncompliant with the drug court program may have been victimized while they resided in their communities.

Further research is needed to identify the reasons that the drug court grant program was the only one of six Department of Justice grants that consistently demonstrated positive associations with crime in this analysis. Additional studies that separately analyze the outcomes of drug courts that immediately incarcerate noncompliant dropouts from courts that do not utilize this approach are also needed. More rigorous evaluations that include experimental design and cost benefit analyses of postprogram outcomes among both graduates and nongraduate dropouts would also be beneficial.

\section{Policy Implications}

Numerous recent studies suggest that drug courts reduce the recidivism of individuals who successfully complete the program. Nothing in the current analysis contradicts that finding. What this first ever nationwide jurisdiction-level study does point out, however, is that the process or implementation of drug court programs from 1995 to 2002 may have led to unintended consequences for communities by resulting in small to moderate crime rate increases. Regardless of whether this positive crime association directly resulted from noncompliant individuals, drug court dropouts, or another related factor, it is clear that programmatic adjustments could improve the effectiveness of the drug court program with regard to community and jurisdiction-level outcomes.

Participants with extensive criminal histories or more serious addiction problems are at increased risk of failure and should be identified at the outset so that additional assistance can be provided. Additionally, drug court procedures should be designed to more quickly identify noncompliant individuals and ensure that they do not remain unsupervised and unaccountable in the community for extended periods of time (including those who are removed from the program). Moreover, the legal authority of drug court judges to incarcerate noncompliant individuals should be clearly specified so that persons who are diverted prior to trial for burglary, vehicle theft, or other offenses cannot find a loophole in the process. Alternatively, drug courts could be limited strictly to postconviction individuals.

Drug courts substantially differ with regard to how closely participants are monitored, responses to noncompliance, and handling of those who are removed from the program. At present, much remains unclear regarding the specific mechanisms by which drug court implementation funding was associated with crime increases. The good news regarding the findings of this analysis, however, is that these relatively minor but important programmatic adjustments would be simple and inexpensive to enact. If implemented in a manner that is consistent with both treatment and crime control objectives, these procedural adjustments have the potential to substantially reduce or eliminate unintended community level outcomes associated with the drug court program.

\section{References}

[1] S. Belenko, Research on Drug Courts: A Critical Review 2001 Update, National Center on Addiction and Substance Abuse (CASA), Columbia University, New York, NY, USA, 2001.

[2] S. Turner, D. Longshore, S. Wenzel et al., National Evaluation of 14 Drug Courts. Rand Corporation, National Institute of Justice, Washington, DC, USA, 2001.

[3] D. B. Wilson, O. Mitchell, and D. L. MacKenzie, "A systematic review of drug court effects on recidivism," Journal of Experimental Criminology, vol. 2, no. 4, pp. 459-487, 2006.

[4] D. Lilley and R. Boba, "A comparison of outcomes associated with two key law-enforcement grant programs," Criminal Justice Policy Review, vol. 19, no. 4, pp. 438-465, 2008. 
[5] T. D. Miethe, H. Lu, and E. Reese, "Reintegrative shaming and recidivism risks in drug court: explanations for some unexpected findings," Crime and Delinquency, vol. 46, no. 4, pp. 522541, 2000.

[6] R. Peters, A. Haas, and M. Hunt, "Treatment "dosage" effects in drug court programs," Journal of Offender Rehabilitation, vol. 33, no. 4, pp. 63-72, 2002.

[7] J. L. Worrall, S. Hiromoto, N. Merritt, D. Du, J. O. Jacobson, and M. Y. Iguchi, "Crime trends and the effect of mandated drug treatment: evidence from California's substance abuse and crime prevention act," Journal of Criminal Justice, vol. 37, no. 2, pp. 109-113, 2009.

[8] Bureau of Justice Assistance, Assessment of the Feasibility of Drug Night Courts, NCJ, 142415, U.S. Department of Justice, Washington, DC, USA, 1993.

[9] Government Accountability Office, Drug Courts: Overview of Growth, Characteristics, and Results, U.S. General Accounting Office, Washington, DC, USA, 1997.

[10] Supreme Court Task Force, Report on Florida's Drug Courts, Office of the State Courts Administrator/Office of Court Improvement, Tallahassee, Fla, USA, 2004.

[11] Government Accountability Office, Adult Drug Courts: Evidence Indicates Recidivism Reductions and Mixed Results for Other Outcomes, U.S. Government Accountability Office, Washington, DC, USA, 2005.

[12] Drug Court Program Office and Office of Justice Programs, Defining Drug Courts: The Key Components, U.S. Department of Justice, Washington, DC, USA, 1997.

[13] A. Armstrong, "Drug courts and the de facto legalization of drug use for participants in residential treatment facilities," Journal of Criminal Law and Criminology, vol. 94, no. 1, pp. 133$168,2003$.

[14] S. L. Burns and M. Peyrot, "Tough love: nurturing and coercing responsibility and recovery in California drug courts," Social Problems, vol. 50, no. 3, pp. 416-438, 2003.

[15] E. Wolf, K. Sowards, and D. Wolf, "Predicting retention of drug court participants using event history analysis," Journal of Offender Rehabilitation, vol. 37, no. 3-4, pp. 139-162, 2003.

[16] Government Accountability Office, Community Policing Grants: COPS Grants Were a Modest Contributor to Declines in Crime During The 1990s, U.S. Government Accountability Office, Washington, DC, USA, 2005.

[17] J. R. Hepburn and A. N. Harvey, "The effect of the threat of legal sanction on program retention and completion: is that why they stay in drug court?" Crime and Delinquency, vol. 53, no. 2, pp. 255-280, 2007.

[18] Crime Control Digest, "Florida: Drug court judges get sanction authority," 2006.

[19] Florida House Bill 175, "Drug court programs. Florida Senate," 2008, http://www.flsenate.gov/data/session/2006/House/bills/ analysis/pdf/h0175c.JUVJ.pdf.

[20] C. Huddleston, K. Freeman-Wilson, and D. Boone, Painting the Current Picture: A National Report Card on Drug Courts and other Problem Solving Court Programs in the U.S, National Drug Court Institute, Alexandria, Va, USA, 2004.

[21] S. Belenko, Research on Drug Courts: A Critical Review 1999 Update, National Center on Addiction and Substance Abuse (CASA), Columbia University, New York, NY, USA, 1999.

[22] J. Roman, W. Townsend, and A. Bhati, Recidivism Rates for Drug Court Graduates: Nationally Based Estimates, U.S. Department of Justice, Washington, DC, USA, 2003.
[23] J. Bowers, "Contraindicated drug courts," UCLA Law Review, vol. 55, no. 4, pp. 783-835, 2008.

[24] J. M. Miller and J. E. Shutt, "Considering the need for empirically grounded drug court screening mechanisms," Journal of Drug Issues, vol. 31, no. 1, pp. 91-106, 2001.

[25] M. Schiff and C. Terry, "Predicting graduation from Broward County's dedicated drug treatment court," The Justice System Journal, vol. 19, pp. 291-310, 1997.

[26] S. R. Senjo and L. A. Leip, "Testing and developing theory in drug court: a four-part logit model to predict program completion," Criminal Justice Policy Review, vol. 12, pp. 66-87, 2001.

[27] M. D. Anglin and G. Speckart, "Narcotics use and crime: a multisample, multimethod analysis," Criminology, vol. 26, no. 2, pp. 197-233, 1988.

[28] D. Boyum and M. Kleiman, "Breaking the drug-crime link," in The Public Interest, vol. 152, pp. 19-38, 2003.

[29] P. Goldstein, P. Bellucci, B. Spunt, and T. Miller, "Frequency of cocaine use and violence: a comparison between men and women," NIDA Research Monograph 110, U.S. Government Printing Office, Washington, DC, USA, 1991.

[30] Health and Human Services, "National household survey on drug abuse: drug use and arrests Table 13.3," 2008, http://www. oas.samhsa.gov/nhsda/1997Main/nhsda1997mfWeb-119.htm \#table13.3.

[31] Bureau of Justice Statistics, Comparing Federal and State Prison Inmates-1991, NCJ, 145864, U.S. Department of Justice, Washington, DC, USA, 1994.

[32] Office of National Drug Control Policy, "Drug policy information clearinghouse: fact sheet," 2000, http://www.whitehousedrugpolicy.gov/publications/factsht/crime/index.html.

[33] Office of Justice Programs, Drug Court Activity Update: Summary Information on All Programs and Detailed Information on Adult Drug Courts, Drug Court Clearinghouse and Technical Assistance Project, Washington, DC, USA, 2001.

[34] D. C. Gottfredson, B. W. Kearley, and S. D. Bushway, "Substance use, drug treatment, and crime: an examination of intra-individual variation in a drug court population," Journal of Drug Issues, vol. 38, no. 2, pp. 601-630, 2008.

[35] C. Lum, The spatial relationship between street-level drug activity and violence [M.S. thesis], University of Maryland, College Park, Md, USA, 2003.

[36] D. Lilley, Assessing jurisdiction-level crime trends during the 1990s: an analysis of the impact of policing changes [M.S. thesis], Michigan State University, East Lansing, Mich, USA, 2006.

[37] M. T. French, K. A. McGeary, D. D. Chitwood, C. B. McCoy, J. A. Inciardi, and D. McBride, "Chronic drug use and crime," Substance Abuse, vol. 21, no. 2, pp. 95-109, 2000.

[38] D. S. Lipton and B. D. Johnson, "Smack, crack, and score: two decades of NIDA-funded drugs and crime research at NDRI 1974-1994," Substance Use and Misuse, vol. 33, no. 9, pp. 1779$1815,1998$.

[39] O. Mitchell, D. B. Wilson, A. Eggers, and D. L. MacKenzie, "Assessing the effectiveness of drug courts on recidivism: a meta-analytic review of traditional and non-traditional drug courts," Journal of Criminal Justice, vol. 40, no. 1, pp. 60-71, 2012.

[40] D. Gottfredson, S. Najaka, and B. Kearley, "Effectiveness of drug treatment courts: evidence from a randomized trial," Criminology and Public Policy, vol. 2, no. 2, pp. 171-196, 2003.

[41] National Institute of Justice, Drug Courts: The Second Decade, National Institute of Justice, Washington, DC, USA, 2006. 
[42] P. Downey and J. Roman, A Bayesian Analysis Meta-Analysis of Drug Court Cost Effectiveness, Urban Institute, Washington, DC, USA, 2010.

[43] Office of Management and Budget, "Program assessment: drug courts. Expectmore.gov Website," 2007, http://www.whitehouse.gov/omb/expectmore/summary/10000168.2002.html.

[44] P. Allison, Fixed-Effects Regression Methods for Longitudinal Data Using SAS, SAS Institute, Cary, NC, USA, 2005.

[45] E. Frees, Longitudinal and Panel Data: Analysis and Applications in the Social Sciences, Cambridge University Press, Cambridge, UK, 2004.

[46] J. Wooldridge, Introductory Econometrics: A Modern Approach, South- Western College, Mason, Ohio, USA, 2000.

[47] M. Leymon, Fixed sentencing: the effects on imprisonment rates over time [M.S. thesis], University of Oregon, Eugene, Ore, USA, 2010.

[48] T. B. Marvell and C. E. Moody, "Specification problems, police levels, and crime rates," Criminology, vol. 34, no. 4, pp. 609-646, 1996.

[49] D. Lilley and R. Boba, "Crime reduction outcomes associated with the State Criminal Alien Assistance Program," Journal of Criminal Justice, vol. 37, no. 3, pp. 217-224, 2009.

[50] J. Worrall, “The effects of local law enforcement block grants on serious crime," Criminology \& Public Policy, vol. 7, no. 3, pp. 325-350, 2008.

[51] J. Zhao, M. Scheider, and Q. Thurman, "Funding community policing to reduce crime: have cops grants made a difference?" Criminology and Public Policy, vol. 2, no. 1, pp. 7-32, 2002.

[52] B. L. Benson, D. W. Rasmussen, and I. Kim, "Deterrence and public policy: trade-offs in the allocation of police resources," International Review of Law and Economics, vol. 18, no. 1, pp. 77-100, 1998.

[53] Federal Bureau of Investigation, Crime in the United States: 2002 Uniform Crime Reports, U.S. Department of Justice, Washington, DC, USA, 2002.

[54] M. D. Maltz, Bridging Gaps in Police Crime Data, U.S. Department of Justice, Bureau of Justice Statistics, Washington, DC, USA, 1999.

[55] J. L. Worrall and T. V. Kovandzic, "Cops grants and crime revisited," Criminology, vol. 45, no. 1, pp. 159-190, 2007.

[56] Bureau of Justice Assistance, "Drug court discretionary grant program,” 2007, http://www.ojp.usdoj.gov/BJA/grant/drugcourts.html.

[57] National Center for Health Statistics, "National vital statistics system: data files and documentation," 2006, http://www.cdc. gov/nchs/about/major/dvs/popbridge/datadoc.htm.

[58] S. Levitt, "Using electoral cycles in police hiring to estimate the effect of police on crime: reply," American Economic Review, vol. 92, no. 4, pp. 1244-1250, 2002.

[59] T. V. Kovandzic and J. J. Sloan, "Police levels and crime rates revisited: a county-level analysis from Florida (1980-1998)," Journal of Criminal Justice, vol. 30, no. 1, pp. 65-76, 2002.

[60] A. Blumstein and J. Wallman, The Crime Drop in America, Cambridge University Press, Cambridge, UK, 2000.

[61] F. Zimring, The Great American Crime Decline, Oxford University Press, New York, NY, USA, 2007.

[62] L. Hannon and P. Knapp, "Reassessing nonlinearity in the urban disadvantage/violent crime relationship: an example of methodological bias from log transformation," Criminology, vol. 41, no. 4, pp. 1427-1448, 2003.
[63] B. Benson and P. Zimmerman, Handbook on the Economics of Crime, Edward Elgar, Northampton, Mass, USA, 2010.

[64] W. Spelman, "Specifying the Relationship Between Crime and Prisons," Journal of Quantitative Criminology, vol. 24, pp. 149178, 2008.

[65] Bureau of Justice Assistance, "Frequently asked questions series: preplea vs. postplea drug courts," 2003, Drug Court Clearinghouse, http://wwwl.spa.american.edu/justice/documents/ 2011.pdf.

[66] C. A. Saum, F. R. Scarpitti, and C. A. Robbins, "Violent offenders in drug court," Journal of Drug Issues, vol. 31, no. 1, pp. 107-128, 2001.

[67] D. Young, "Impacts of perceived legal pressure on retention in drug treatment," Criminal Justice and Behavior, vol. 29, no. 1, pp. 27-55, 2002.

[68] Bureau of Justice Assistance, "Strategies for dealing with young females who violate the drug court program shortly after entry," 2004, Drug Court Clearinghouse, http://wwwl.spa.american. edu/justice/document_center.php. 

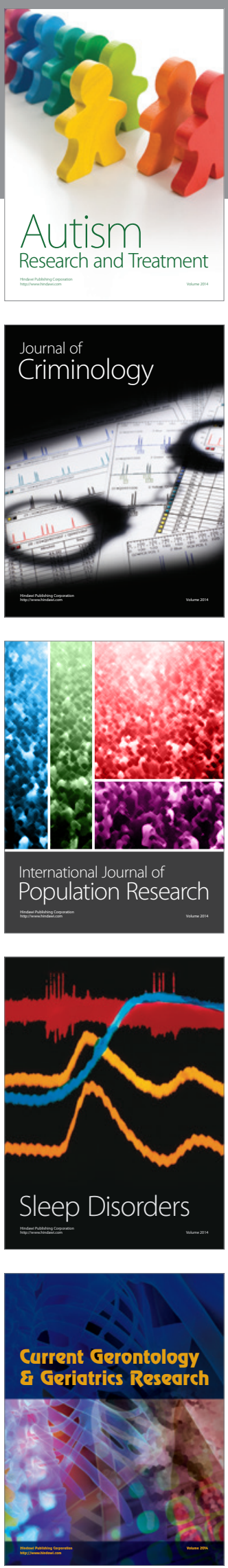
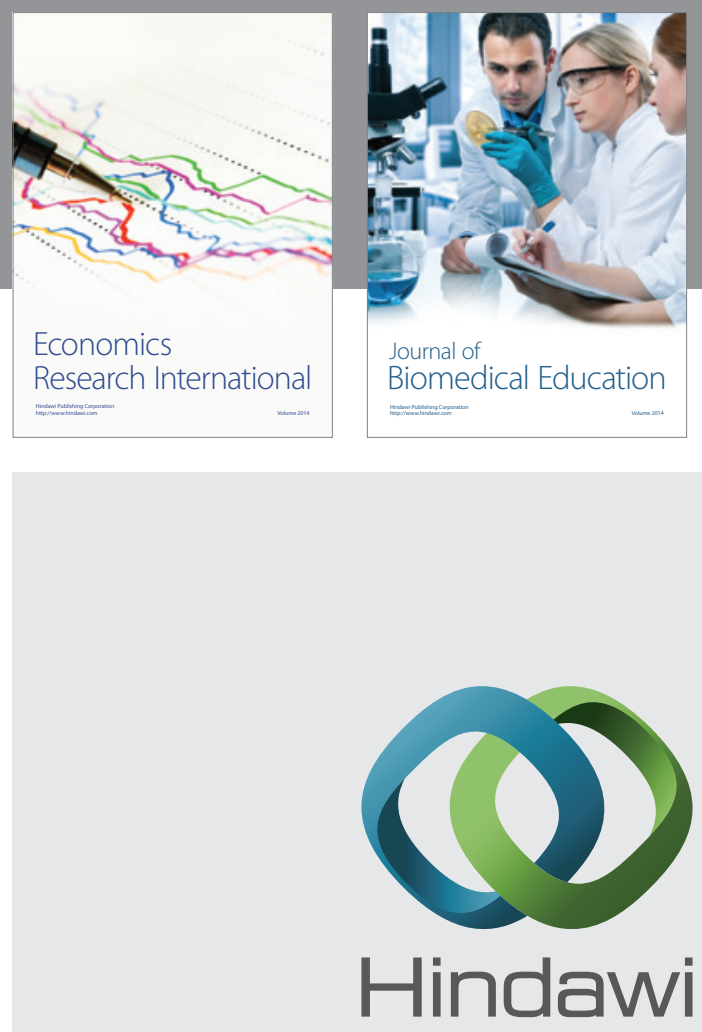

Submit your manuscripts at

http://www.hindawi.com
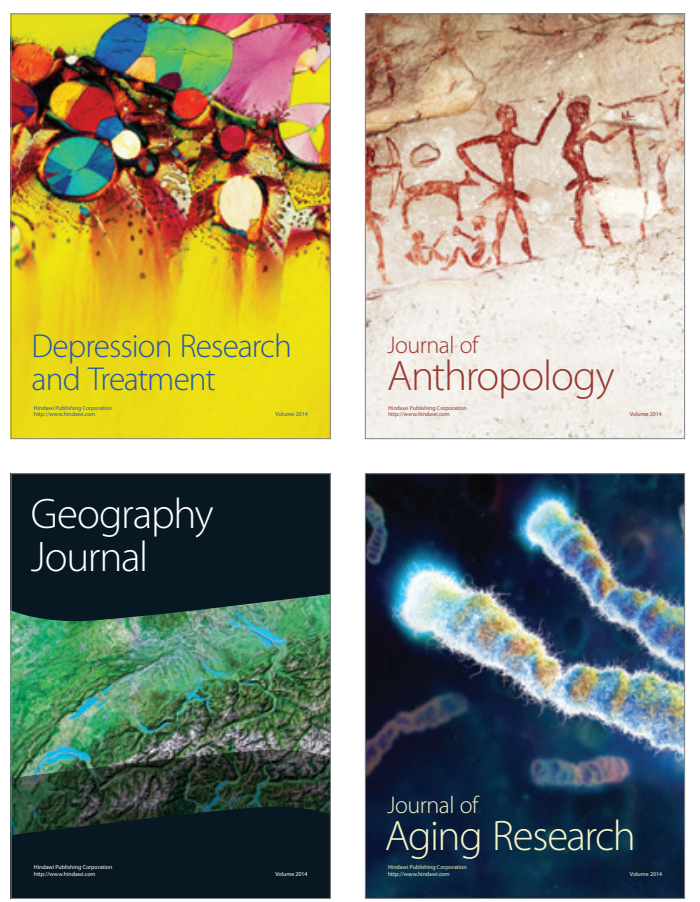
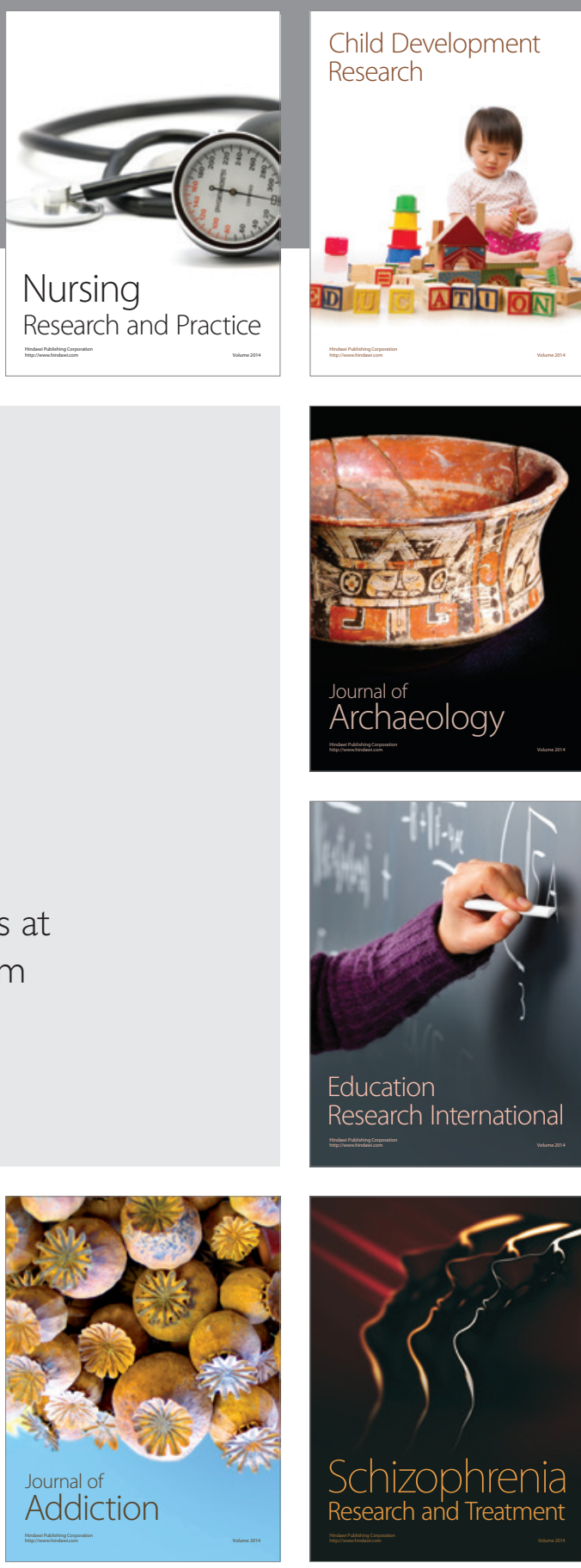

(D)
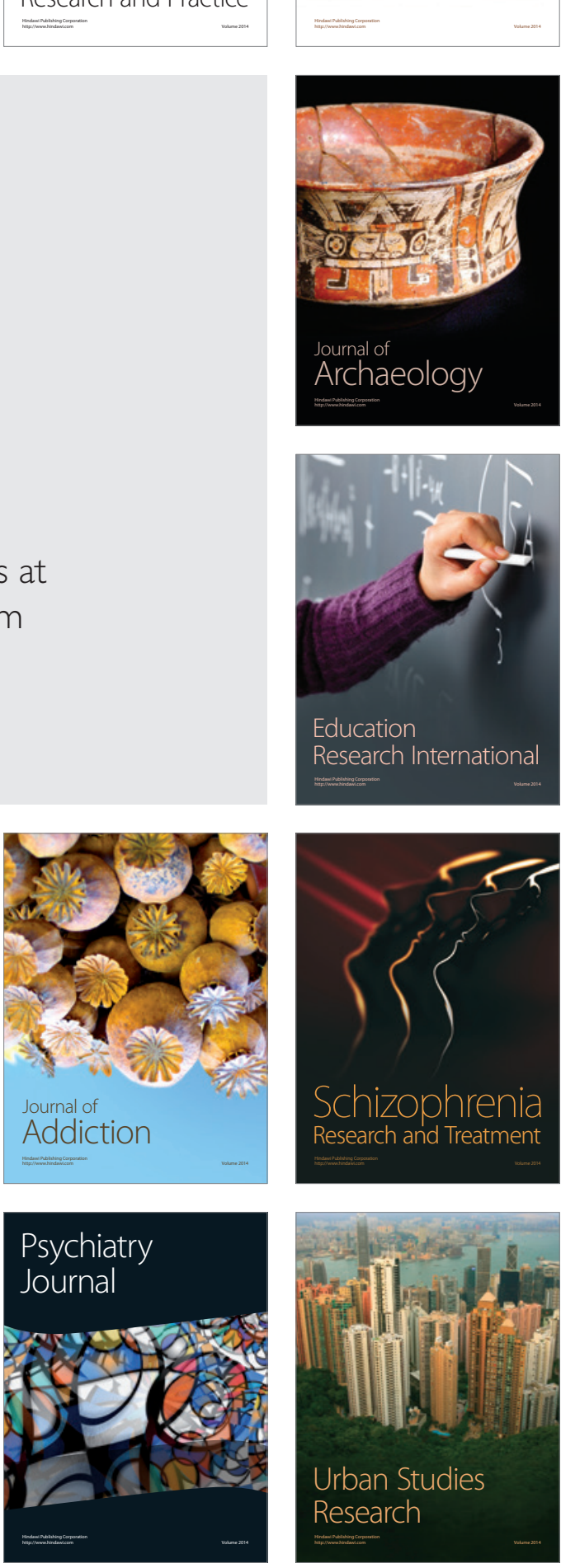